\title{
Potensi Pantai Panrangluhung di Bira Kabupaten Bulukumba sebagai Destinasi Wisata
}

\author{
Muhammad Musawantoro1, Masri Ridwan*2 \\ Politeknik Negeri Pariwisata Makassar, Indonesia ${ }^{1,2}$ \\ Email: masriridwan010@gmail.com
}

\begin{abstract}
This study aims to identify the characteristics of tourism in Panrangluhung Beach, Bira Village, Bontobahari District, Bulukumba Regency, South Sulawesi Province, Indonesia. Data collection techniques by survey, documentation and observation. This study employs spatial analysis and snowball sampling to analyze and collect data on the distribution of accommodation, attractions and tourist attractions at the study site. As for data visualization, geographic information system analysis is then performed with the existing data overlay method. The results show that the Panrangluhung beach area as a typology of marine tourism attraction with a coastline of 1,650 meters and cultural tourism at the center of phinisi shipbuilding. Recommendations from this study are to revitalize the 45-meter long coastal area in the southern part of the study site, including: the installation of a sign system and directing beach cleanliness.
\end{abstract}

Keywords: attraction beach, culture, destinations.

\begin{abstract}
Abstrak
Penelitian ini bertujuan untuk mengidentifikasi karakteristik wisata di Pantai Panrangluhung Desa Bira Kecamatan Bontobahari Kabupaten Bulukumba Provinsi Sulawesi Selatan, Indonesia. Teknik pengumpulan data melalui survey, dokumentasi dan observasi. Penelitian ini menggunakan spatial analisis and snowball sampling untuk menganalisis and mengumpulkan data-data sebaran akomodasi, daya tarik dan atraksi wisata di lokasi penelitian. Sementara untuk visualisasi data, selanjutnya dilakukan analisis system informasi geografis dengan metode overlay eksisting data. Hasil penelitian menunjukkan bahwa kawasan pantai Panrangluhung sebagai tipologi daya tarik wisata bahari dengan garis pantai sepanjang 1,650 meter dan daya tarik wisata budaya pada pusat pembuatan kapal phinisi. Rekomendasi dari penelitian ini adalah melakukan revitalisasi kawasan pantai sepanjang 45 meter di bagian selatan lokasi penelitian, diantaranya: pemasangan sign system (penunjuk arah) dan pembenahan kebersihan pantai.
\end{abstract}

Kata Kunci: objek wisata pantai, budaya, destinasi.

\section{A. PENDAHULUAN}

Salah satu sifat manusia adalah rasa ingin tahu (curiosity) yang tinggi terhadap berbagai hal. Dari sekian banyak keingintahuan manusia adalah ingin tahu tentang wilayah lain di luar wilayahnya. Jauh sebelum orang mengenal adanya bentuk komunikasi dalam bentuk tulisan, manusia telah menjelajahi permukaan bumi dari daerah yang paling dekat dengan tempat tinggalnya. Selanjutnya penjelajahan ini dilakukan sampai agak jauh serta sampai sejauh mungkin yang dapat mereka lakukan. Dari penjelajahan tersebut, mereka sadar akan adanya berbagai macam perbedaan antara tempat atau daerah yang satu dengan daerah lainnya. Perbedaan antara berbagai tempat di permukaan bumi tersebut, baik menyangkut aspek fisik maupun keadaan sosial ekonomi dan budayanya. Pelbagai perbedaan pada wilayah tersebut dalam geografi disebut Geodiversity (James, 1971).

\footnotetext{
* Corresponding author 
Kebutuhan untuk memenuhi rasa ingin tahu terhadap daerah lain ini sama halnya dengan kebutuhan hidup lainnya. Kegiatan ini ditunjang oleh adanya kemajuan teknologi dalam bidang transportasi, sehingga orang dapat melakukan perjalanan ke tempat yang sangat jauh dengan semakin mudah. Kemajuan ekonomi dengan semakin meningkatnya kesejahteraan, serta adanya waktu luangyang meningkat, sangat menunjang dalam pemenuhan kebutuhan ini. Salah satu bentuk pemanfaatan waktu luang ini melakukan kegiatan wisata (Sujali, 1989). Dengan demikian, terdapat daerah sebagai tujuan dan asal wisatawan.

Indonesia sebagai daerah tujuan wisatawan. Sumber daya pariwisata yang melimpah menjadikan Indonesia mempunyai potensi. Keunggulan kompetetif Indonesia di bidang pariwisata menjadi daya tarik tersendiri (Yuli, 2011). Mulai dari potensi sumber daya pariwisata alam, budaya, bahari, sejarah, pedesaan dan perkotaan. Dengan perencanaan dan strategi yang optimal diharapkan Pariwisata di Indonesia dapat menjadi pilar pembangunan. Atas latar belakang tersebut, Kementerian Pariwisata menyusun serangkaian strategi untuk memaksimalkan potensi-potensi di negara yang berjulukZamrud Khatulistiwa ini (Pamungkas, 2019; Pangestu, 2019).

Berdasarkan Penyusunan Strategi Komunikasi Pemasaran Terpadu, Kementerian Pariwisata (2019) telah menetapkan target 20 juta kunjungan wisatawan mancanegara (wisman) di 2019, yang mana setengahnya diharapkan datang dari pasar pariwisata wilayah II (medium dan long haul market). Negara yang menjadi target Kementerian Pariwisata berjumlah 13 negara yaitu: China, India, Jepang, Korea Selatan, Inggris, Amerika Serikat, Hong Kong, Prancis, Jerman, Belanda, Taiwan, Arab Saudi, Russia. Target market tersebut yang menyesuaikan dengan perilaku dan preferensi dari masing-masing negara tersebut ketika melakukan perjalanan liburan agar tepat sasaran dan lebih efisien dalam penyampaian pesan-pesan promosi. Perbedaan atau ke-khasan dan preferensi dari masing-masing negara tersebut akan berpengaruh kepada perbedaan kecenderungan dalam memilih destinasi. Umumnya preferensi adalah mencari tempat yang dapat menawarkan keunikan dan keindahan alam terutama laut dan pantai untuk mencari tempat untuk berjemur, aktivitas yang bersifat outdoor dan pemandangan pantai yang indah. Salah satu potensi budaya dan pantai di Indonesia berada di Kabupaten Bulukumba.

Kabupaten Bulukumba Provinsi Sulawesi Selatan sebagai daerah tujuan wisata. Daerah yang dikenal dengan "Bumi Panrita Lopi" ini sebagai tempat pembuatan kapal phinisi (Jamil, 2017) terdapat sejumlah potensi daya tarik wisata. Peraturan Pemerintah Republik Indonesia Nomor 50 Tahun 2011 Tentang Rencana Induk Pembangunan Kepariwisataan Nasional Tahun 2010-2025 menetapkan kabupaten Bulukumba sebagai kawasan pengembangan pariwisata nasional (KPPN). Sementara Posisi kepariwisataan kabupaten Bulukumba dalam kebijakan pembangunan pariwisata provinsi Sulawesi Selatan ditempatkan sebagai Kawasan Strategis Pariwisata Daerah (KSPD) Bulukumba dan Sekitarnya.

Salah satu potensi yang ada di Kabupaten Bulukumba adalah Pantai Panrangluhung Desa Bira Kecamatan Bontobahari. Daya tarik yang terdapat di lokasi tersebut diantarantya pasir putih, panorama dan aktivitas pembuatan phinisi, perahu kebanggaan masyarakat Sulawesi Selatan. UU No. 9 tahun 1990 tentang kepariwisataan disebutkan bahwa daya tarik wisata adalah suatu yang menjadi sasaran wisata. Di antaranya keadaan alam, flora dan fauna, museum, peninggalan sejarah, seni dan budaya, wisata agro, wisata buru, wisata petualangan alam, taman rekreasi dan kompleks hiburan, mendaki gunung, gua, industri dan kerajinan, tempat perbelanjaan, sungai air deras, tempat-tempat ibadah, tempat ziarah dan lain-lain.

Selain Pantai Panrangluhung, terdapat daya tarik lainnya yang berada di kawasan bira. Di antaranya, Pua Janggo (Pelras, 1993), Makam Dato Tiro (Suriani, 2017), Permandian Hila-hila (Bahtiar, 2016), Pantai Lolisang dan Pantai Samboang. Angka kunjungan ke kawasan ini selama 3 tahun terakhir mengalami peningkatan, selama tahun 2016, 2017 dan 2018 total pengunjung secara berurutan diantaranya 175.455/ tahun, 203.934/ tahun dan 262.225/ tahun (Dispar Bulukumba, 2018). Akan tetapi untuk kunjungan ke Pantai Panrangluhung oleh sejumlah

2 | Jurnal Kepariwisataan: Destinasi, Hospitalitas dan Perjalanan, Volume 3 Nomor 1, 2019: 1-7 
narasumber tidak mengalami peningkatan, hal ini disebabkan kurangnya informasi keberadaan pantai ini, mulai dari informasi daya tarik, ketersediaan akomodasi hingga amenitas.

Dengan memanfaatkan teknologi Sistem Informasi Geografi (SIG) diharapkan mampu untuk menganalisis aspek ruang pada suatu daerah sehingga potensi-potensi wisata yang ada dapat dikembangkan menjadi obyek dan daya tarik wisata secara optimal yang dapat menarik kunjungan wisatawan baik domestik maupun mancanegara. Penelitian Agus dan Masri (2019) bertujuan mengetahui sebaran daerah tujuan wisata Kabupaten Kepulauan Selayar sebagai salah satu unsur penunjang sektor pariwisata. Serta Ridwan, Masri (2019) tentang inventarisasi potensi wisata di Kabupaten Sinjai, Hasil penelitian menunjukkan bahwa: 1) potensi objek wisata Kabupaten Sinjai terdiri 34 objek wisata alam, 71 objek wisata sejarah dan budaya dan 17 objek wisata minat khusus buatan manusia 2) Objek wisata Kabupaten Sinjai menghasilkan data geografis berupa data atribut dan spasial yang tersebar tiap kecamatan.

Salah satu strategi pemasaran pariwisata dengan menyajikan latar belakang atau setting visual yang mencakup keindahan alam suatu daerah, dinamika kota, landmark daerah, arsitektur heritage khas daerah, dan lain-lain. Oleh karena itu, penting dilakukan kajian secara visual untuk sebaran daya tarik dan sarana prasarana penunjang di Pantai Panrangluhung dengan memanfaatkan penginderaan jauh dan SIG. melalui penyajian secara visual diharapkan dapat menarik minat wisatawan berkunjung ke destinasi ini.

\section{B. METODE PENELITIAN}

Penelitian ini menggunakan pendekatan kualitatif. Moleong (2007) Penelitian kualitatif menggunakan metode kualitatif yaitu pengamatan, wawancara, atau penelaahan dokumen. Penelitian kualitatif untuk mengamati dan menulis tentang fenomena yang terjadi. Metode pengambilan data secara survey.

Singarimbun (1982) dalam metode penelitian survey mengatakan bahwa penelitian survey adalah "penelitian yang mengambil sampel dari satu populasi dan menggunakan kuesioner sebagai alat pengumpulan data yang pokok dengan melibatkan teknik penelitian survei, wawancara, catatan lapangan dan dokumentasi. Data Primer diperoleh dengan melakukan survei ke lokasi penelitian, pencatatan fenomena yang terjadi serta melakukan dokumentasi objek. Data Sekunder, diperoleh dengan observasi dan wawancara sejumlah pihak terkait, misalnya Dinas Pariwisata dan Kebudayaan Kabupaten Bulukumba, Pengelolah Cottage, Hotel dan Penginapan, wisatawan serta kajian refrensi. Sementara hasil pengamatan dan temuan di lapangan dianalisis dengan metode deskripsi kualitatif dan menggunakan bantuan software ArcGIS dengan memvisualisasikan data, berupa data spasial dan deskripsi.

Bernharsen dalam Rosana (2003) mendefinisikan: "Sistem Informasi Geografi adalah sistem komputer yang digunakan untuk akuisisi (perolehan) dan verifikasi, kompilasi, penyimpanan, perubahan (updating) manajemen dan pertukaran, manipulasi, pemanggilan dan presentasi, serta analisis data geografis". Sistem komputer yang digunakan untuk memasukkan (capturing), menyimpan, memeriksa, mengintegrasikan, memanipulasi, menganalisis, dan menampilkan data, berhubungan dengan posisi di permukaan bumi. Dengan demikian, diperoleh gambaran yang komprehensif berupa data grafis-atribut dan deskripsi tentang keberadaan pantai Panrangluhung Desa Bira Kabupaten Bulukumba.

\section{Lokasi Penelitian}

Pantai Panrangluhung berada di Desa Bira Kecamatan Bontobahari Kabupaten Bulukumba. Pantai Panrangluhu berada di Kecamatan Bontobahari. Dijangkau dari ibu kota Bulukumba selama 1 jam perjalanan. Secara Geografis lokasi ini mempunyai batas bagian Utara terdapat Kecamatan Bontotiro, bagian Timur terdapat Teluk Bone, bagian Selatan terdapat Pulau Selayar dan Pulau Liukanglu serta bagian barat Bara terdapat Kabupaten Bantaeng, dan Laut Flores. 


\section{Data yang digunakan}

Data yang digunakan dalam penelitian ini adalah

a. Data Sebaran Daya tarik wisata tahun 2018.

b. Data Ketersediaan Sarana dan Prasana inudstri pariwisata 2018

c. Peraturan Daerah RTRW Kabupaten Bulukumba 2012-2032

d. Data Elevation Model Nasional DEMNAS-BIG

e. Data Survey Lapangan.

\section{Alat dan Bahan}

Alat dan bahan yang digunakan pada penelitian ini meliputi perangkat keras dan perangkat lunak. Perangkat keras yang digunakan terdiri dari satu unit komputer brand Acer dengan spesifikasi Processor AMDA Ryzen 52500 U Radeon Vega Graphics (R) Core (tm) i5-2450 M CPU @2,50 GHZ, Memory 8 GB; Sistem Operasi: Microsoft Windows 10 dan perangkat lunak yang digunakan meliputi:

a. ArcGIS versi 10.5 sebagai perangkat lunak

b. Corel Draw X-8

c. Perangkat lunak pengolah kata dan spreadsheet (MS Word dan MS Excel) untuk penyusunan laporan dan pengolahan data tabuler;

d. Global Positioning System (GPS) merk Garmin, digunakan sebagai alat bantu dalam menentukan arah atau posisi di lapangan; dan;

e. Camera Canon untuk merekam obyek-obyek penting di lapangan.

\section{HASIL DAN ANALISIS}

\section{Sebaran Akomodasi}

Berdasarkan data yang diperoleh dari Observasi lapangan dan Wawancara di Dinas Pariwisata dan Kebudayaan serta Bapedda untuk ketersedian akomodasi di kawasan pantai Panrangluhung seperti dalam tabel 1.

Tabel 1. Sebaran Akomodasi Pantai Panrangluhung Tanjung Bira

\begin{tabular}{|c|c|c|c|c|c|}
\hline Penginapan & Telp-Hp & Tipe Kamar & Spesifikasi & Unit & Tarif \\
\hline \multirow{2}{*}{$\begin{array}{l}\text { Villa Artha } \\
\text { Bira }\end{array}$} & \multirow[t]{2}{*}{085340596491} & Standar & AC,ranjangTV,WC & 2 & 500.000 \\
\hline & & Standar & $\begin{array}{l}\text { Kipas } \\
\text { ranjang,TV,WC }\end{array}$ & 2 & 350.000 \\
\hline \multirow[t]{4}{*}{$\begin{array}{l}\text { Kaluku } \\
\text { Cottage }\end{array}$} & \multirow[t]{4}{*}{085656587458} & Family Room & $\begin{array}{l}\text { AC,Air panas, Tv, } \\
\text { Kulkas }\end{array}$ & 1 & 1150.000 \\
\hline & & $\begin{array}{l}\text { Cottege } \\
\text { Deluxe }\end{array}$ & $\begin{array}{l}\text { ranjangTV,WC, sea } \\
\text { view }\end{array}$ & 1 & 1250.000 \\
\hline & & Standar & AC,ranjang, Kulkas & 1 & 450.000 \\
\hline & & Deluxe & $\begin{array}{l}\text { AC,ranjang } \\
\text { Kulkas,Move View }\end{array}$ & 2 & 550.000 \\
\hline $\begin{array}{l}\text { Wisma Dua } \\
\text { Putri }\end{array}$ & 085656587458 & Baruga & $\begin{array}{l}\text { AC,ranjangTV,WC, } \\
\text { Kulkas, dapur }\end{array}$ & 1 & 1.000 .000 \\
\hline \multirow[t]{2}{*}{$\begin{array}{c}\text { Villa Panrang } \\
\text { Luhu }\end{array}$} & \multirow[t]{2}{*}{085394416213} & Standar & $\begin{array}{l}\text { Kipas } \\
\text { Angin,TV,Ranjang }\end{array}$ & 2 & 300.000 \\
\hline & & Standar & AC,TV,Ranjang & 2 & 400.000 \\
\hline $\begin{array}{l}\text { Villa Keluarga } \\
\text { Panrang Luhu }\end{array}$ & 082395247399 & Standar & $\mathrm{AC}, \mathrm{WC}, \mathrm{TV}$, ranjang & 4 & 400.000 \\
\hline
\end{tabular}

4 Jurnal Kepariwisataan: Destinasi, Hospitalitas dan Perjalanan, Volume 3 Nomor 1, 2019: 1-7 


\section{Sebaran Daya Tarik}

Survei lapangan dilakukan dengan menggunakan alat GPS Handheld dan camera untuk mendapatkan data spasial dan data non spasial dari lokasi yang dijadikan fokus kajian. Potensi yang berada di Pantai Panrangluhung terdiri dari daya tarik wisata pantai dan budaya. Dalam tabel 2 diapaparkan sebaran daya tarik yang berada di lokasi penelitian.

Tabel 2. Sebaran Daya Tarik Wisata Pantai Panrangluhung



Sumber data: Survei lapangan, 2019

Berdasarkan hasil survey lapangan, selanjutnya tahapan visualisasi data yaitu setelah mendapatkan titik koordinat setiap lokasi dan database, kemudian melakukan proses layout peta yaitu dengan menampilkan setiap titik lokasi wisata di peta untuk menunjukkan posisi dari lokasi wisata 
tersebut di peta sehingga masyarakat secara umum dan turis secara khusus dapat dengan mudah mengidentifikasi spot-spot yang berada di Pantai Panrangluhung.

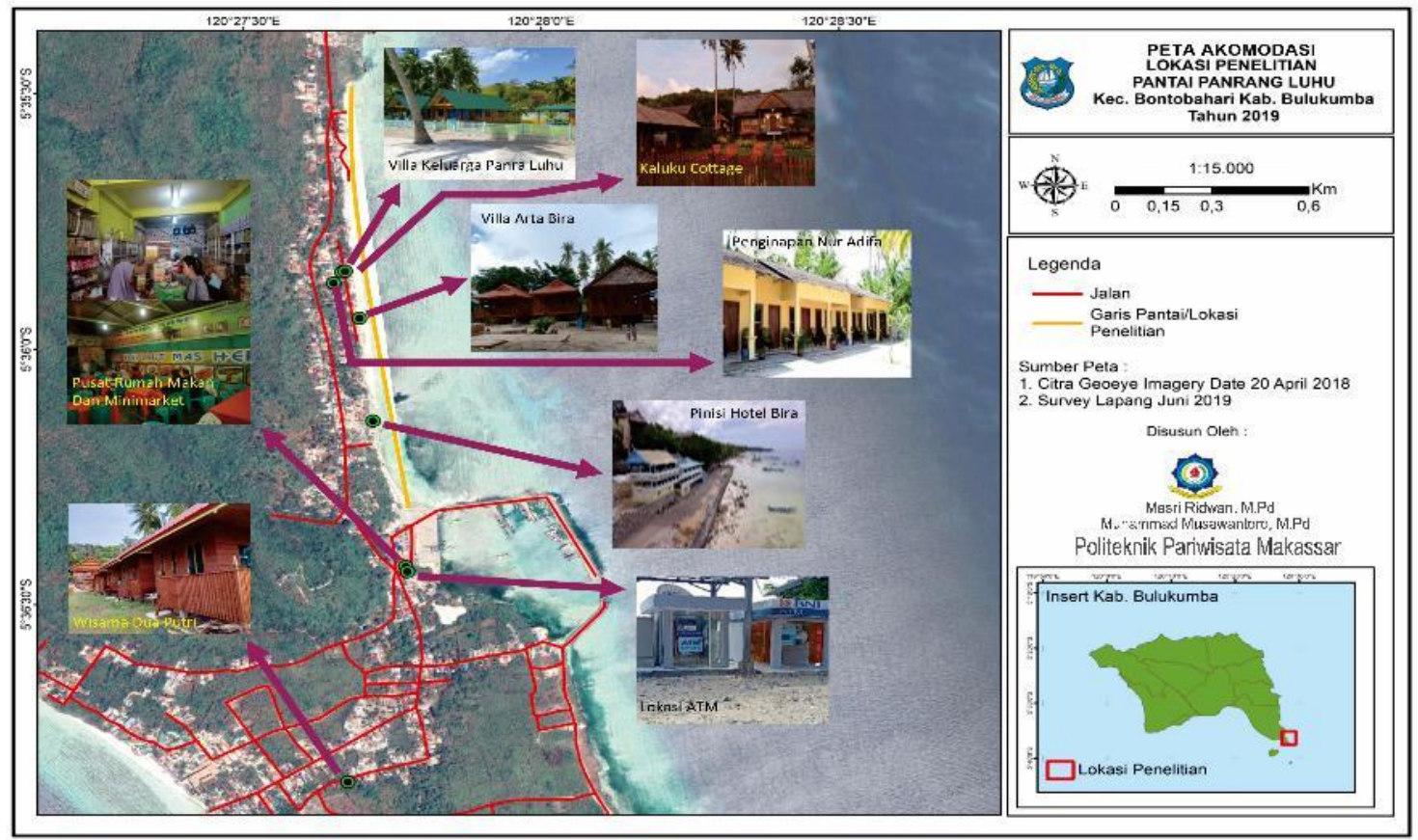

\section{Gambar 1 Pemetaan Lokasi Wisata}

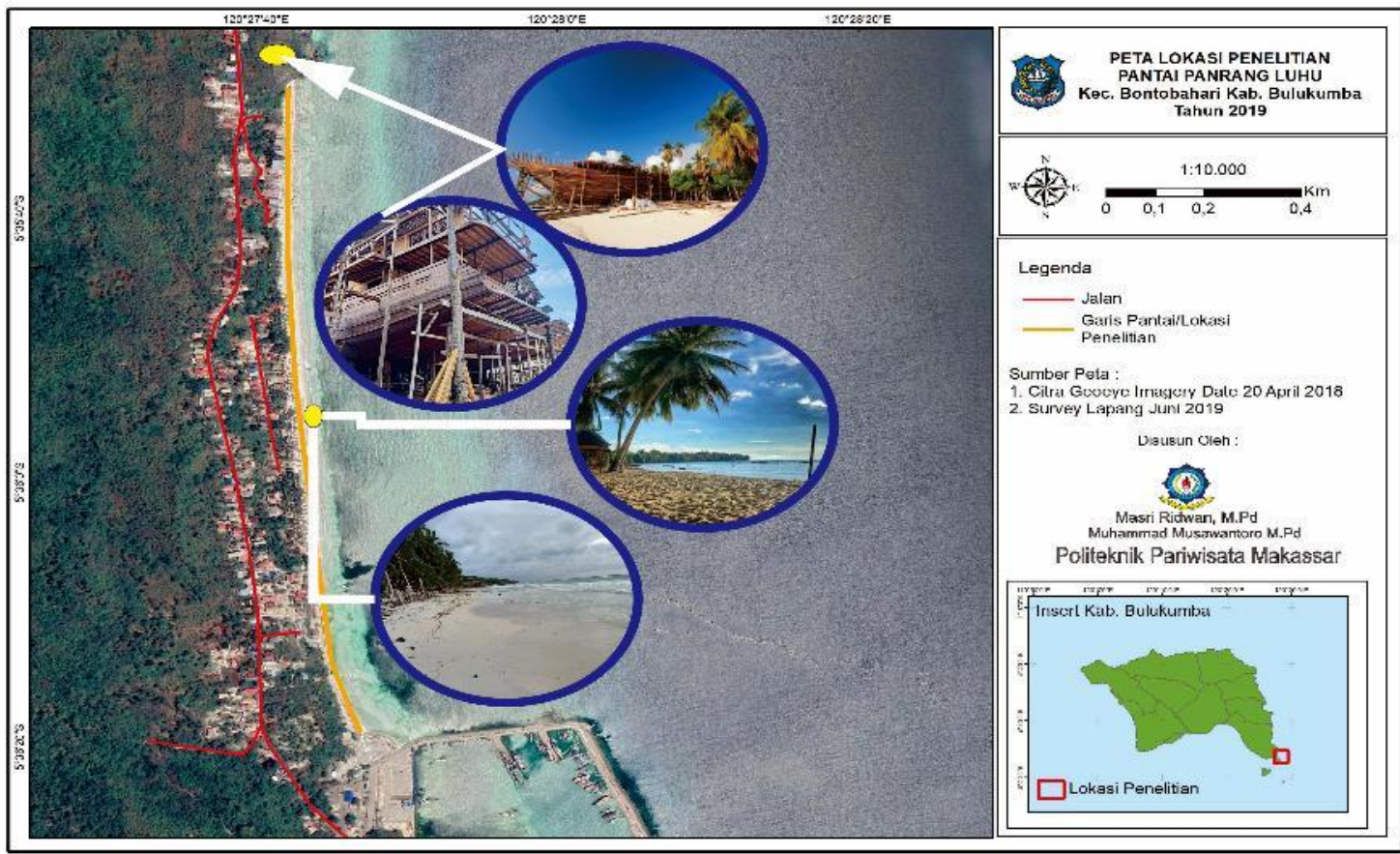

Gambar 2 Pemetaan Atraksi Wisata

6 Jurnal Kepariwisataan: Destinasi, Hospitalitas dan Perjalanan, Volume 3 Nomor 1, 2019: 1-7 


\section{SIMPULAN}

Daya Tarik Wisata yang terdapat di Pantai Panrangluhung meliputi daya tarik wisata Bahari dan Budaya. Untuk daya tarik wisata pantai/ bahari, Wisatawan dapat melakukan aktivitas diantaranya : Berenang, Diving, Rekreasi Pantai dan Banana Boat. Sementara daya tarik wisata budaya, wisatawan dapat melakukan aktivitas wisata diantaranya mengamati Kearifan lokal dan tuntutan hidup masyarakat di Kawasan Pantai Panrangluhung sebagai pembuat perahu phinisi "Panrita Lopi", Contemporary Art, Storytelling" Phinisi oleh masyarakat lokal dan Kebiasaan.

Fasilitas penunjang yang terdapat di Pantai Panrangluhung meliputi ketersediaan akomodasi, amenitas dan atraksi wisata. Pemetaan Pantai Panrangluhung terdiri dari data grafis dan atribut masingmasing spot.

\section{DAFTAR REFERENSI}

Agus, Ridwan, Masri. (2019). Pemetaan Objek Wisata Alam Kabupaten Kepulauan Selayar Berbasis Sistem Informasi Geografis Arcgis 10.5. PUSAKA (Journal of Tourism, Hospitality, Travel and Business Event) 1 (1), 45-50.

Bahtiar, B. (2016). Islamisasi Di Tiro Bulukumba. Al-Qalam, 18(2), 227-235.

Bappeda Kabupaten Bulukumba, 2019. Arsip

Block, James H. (1971). Mastery learning : Theory and practice. New York : Holt, Rinehart and Winston, Inc.

Dinas Pariwisata Kabupaten Bulukumba, 2019. Arsip

Jamil, K. N. (2017). Perahu Pinisi Sebagai Lambang Kabupaten Bulukumba (Analisis Semiotika Charles Sanders Pierce) (Doctoral dissertation, UIN Alauddin Makassar).

Kementerian Pariwisata dan Ekonomi Kreatif / Badan Pariwisata dan Ekonomi Kreatif Republik Indonesia. (2019). Penyusunan Strategi Komunikasi Pemasaran Terpadu. Markplus.inc: The Leading Marketing Consulting in Indonesia.

Moleong, Lexy J. (2007). Metodologi Penelitian Kualitatif, Penerbit PT Remaja Rosdakarya. Offset, Bandung.

Pamungkas, B. T. (2019). Strategi Pemerintah Kabupaten Semarang Dalam Pengembangan Potensi Pariwisata Di Candi Gedong Songo. Journal of Politic and Government Studies, 8(04), 101110.

Pangestu, Y. H. (2019). Strategi Pengembangan Objek Wisata Bahari Dalam Meningkatkan Pendapatan Daerah Kabupaten Pesawaran (Studi Pengembangan Objek Wisata Bahari Pulau Pahawang).

Pelras, C. (1993). Religion, tradition, and the dynamics of Islamization in South Sulawesi. Indonesia, (57), 133-154.

Ridwan, Masri. 2019. Prosiding Seminar Nasional Pariwisata "Indonesia Sebagai Pusat Wisata Bahari Dunia: Inventory of tourism object based on Sinjai district Geographic information system (software Arcgis 10.5). Politeknik Pariwisata Makassar.

Rosana. (2003). Kartografi Bahan Ajar. FKIP UNILA. Bandar Lampung

Singarimbun, Masri dan Sofian Effendi. (1989). Metode Penelitian Survey. LP3ES. Jakarta

Sujali, (1989). Geografi Pariwisata dan Kepariwisataan. Fakultas Geografi UGM. Yogyakarta.

UU No. 9 tahun 1990 tentang kepariwisataan.

Peraturan Pemerintah Republik Indonesia Nomor 50 Tahun 2011 Tentang Rencana Induk Pembangunan Kepariwisataan Nasional Tahun 2010-2025.

Suriani, S. (2017). Tradisi Ziarah pada Makam Dato Ri Tiro Kecamatan Bontotiro Kabupaten Bulukumba (Doctoral dissertation, Universitas Islam Negeri Alauddin Makassar).

Yuli, A. (2011). City Branding sebagai strategi pengembangan pariwisata ditinjau dari aspek hukum merek (studi kasus city branding daerah istimewa yogyakarta sebagai daerah tujuan wisata unggulan di Indonesia). QISTIE, 5(1). 